\title{
A case of Cows' milk allergy in the syndrome of thrombocytopenia with absent radius
}

\author{
Kankananarachchi I ${ }^{1}$, Rathuwithana RDAC ${ }^{2}$, Vithana SR ${ }^{2}$, Gunawardena TPJG ${ }^{1}$
}

\section{Introduction}

Thrombocytopenia with absent radii (TAR) is a rare congenital disorder with hypomegakaryocytic thrombocytopenia and bilateral radial aplasia. ${ }^{1}$ They presents in early infancy ranging from mild changes to marked limb shortening. About $50 \%$ of the patients with TAR syndrome have cow's milk protein allergy. ${ }^{2}$ Here we report a 2 year old girl with TAR syndrome presented with marked gastrointestinal disturbance and clinical evidence of cows' milk allergy.

\section{Case report}

She was the first child born to non-consanguineous parents following uneventful antenatal period. She had an obvious forearm deformity at birth. (Figure 1)
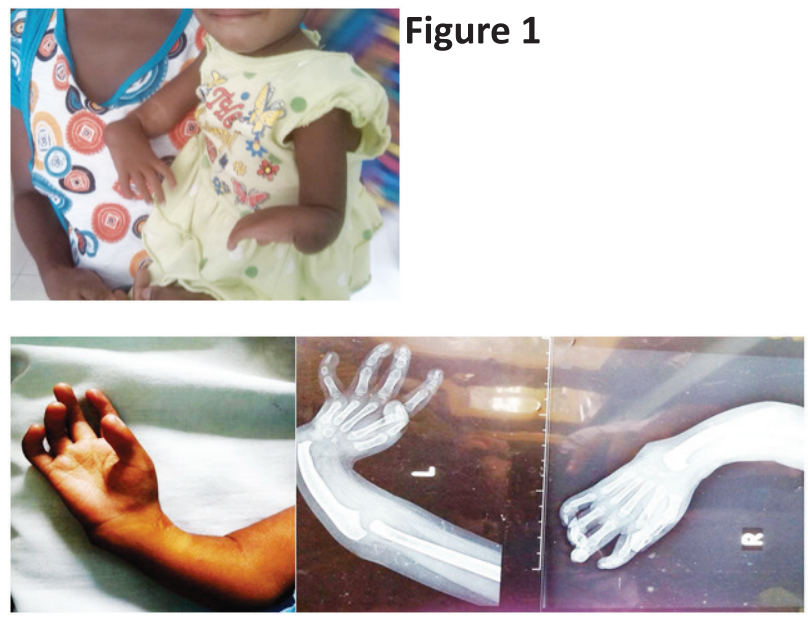

Figure 2

1. Department of Paediatrics, Faculty of Medicine, University of Ruhuna, Sri Lanka

2. University Paediatric Unit, Teaching Hospital, Karapitiya, Sri Lanka

Corresponding author : Imalke Kankananarachchi; imalke462@gmail.com ;

https://orcid.org/0000-0002-9351-2966
There werebilateral radial club hands with radialaplasia, (Figure 2) whereas the rest of the skeleton was normal.

She had thrombocytopenia (30 x 103) with normal other haematologicalindices during neonatal period and has had marked thrombocytopenia during early infancy without any bleeding manifestations which was improved in subsequent full blood counts. Rest of her full blood count parameters was normal. She thrived well with exclusive breastfeeding for six months. There were no concerns with the commencement of complementary feeding. However, since the introduction of cow's milk at 14 months, she developed episodic abdominal distension and blood stained stools with failure to thrive.

Cow's milk products were introduced for the first time around 14 months.The stoolscontained mucus and blood, but repeated stoolculture showed no gastrointestinal pathogens.There were no features of inflammatory bowel disease. Direct relationship with the cow's milk product and the severity of symptoms were observed. Decision was made to withhold the cow's milk products and her gastrointestinal symptoms improved markedly. As a diagnostic trial cow's milk was reintroduced after 2 weeks and she developed similar Gl symptoms again. None of these episodes precipitated haematological relapses. She never had urticaria, vomiting or edema suggestive of Ig E mediated allergy. Child was managed without cow's milk products andshe remained asymptomatic thereafter.

\section{Discussion}

In 1969 TAR syndrome was first defined as amegakaryocytic thrombocytopenia and absent radii. ${ }^{3}$ The molecular basis of TAR syndrome has recently been identified as a microdeletion on Chromosome $1 .{ }^{4}$ Though this child didn't have, Lower limb skeletal abnormalities are also associated with TAR syndrome with lesser frequency.Unlike congenital amegakaryocytic thrombocytopenia (CAMT), platelet count tends to improve in TAR syndrome after 1 year. In this case she had persistently 
normal platelet count since early infancy. ${ }^{5}$

Cow's milk protein allergy is a known association of TAR syndrome. It is well known that haematogical relapses occurs in patients with TAR when they exposes to cow's milk products, this was not evident in this child. Cow's milk protein allergy occurs both in IgE mediated and non IgE mediated ways. This patient had features suggestive of non IgE mediated allergy. Diagnosis of non IgE mediated cow's milk protein allergy is challenging. Food challenge is a one method of diagnosing it. In this child there was a clear relationship with the GI symptoms and the cow's milk products consumption. ${ }^{2}$

The mainstay of treatment for any food allergy is the appropriate identification and elimination of foods responsible forfood hypersensitivity reactions. ${ }^{6}$ At the same time it is important to prevent nutritional deficiencies due to the dietary modification.

Since it's a common association of TAR syndrome, any such children presenting with gastrointestinal symptoms should be evaluated for possible cow's milk protein allergy.

\section{Reference}

1. Hall JG. Thrombocytopenia and absent radius (TAR) syndrome. Journal of medical genetics. 1987 Feb;24(2):79.

2. Whitfield MF, Barr DG. Cows' milk allergy in the syndrome of thrombocytopenia with absent radius. Archives of disease in Childhood. 1976 May 1;51(5):337-43.

3. Hall JG, Levin J, Kuhn JP, Ottenheimer EJ, van Berkum KA, McKusick VA. Thrombocytopenia with absent radius (TAR). Medicine (Baltimore) 1969 Nov;48(6):411-439.

4. Manukjan G, Bösing H, Schmugge $M$, Strauß G, Schulze $\mathrm{H}$. Impact of genetic variants on haematopoiesis in patients with thrombocytopenia absent radii (TAR) syndrome. British journal of haematology. 2017 Nov;179(4):606-17.

5. Greenhalgh KL, Howell RT, Bottani A, Ancliff PJ, Brunner HG, Verschuuren-Bemelmans CC, Vernon E, Brown KW, Newbury-Ecob RA. Thrombocytopenia-absent radius syndrome: a clinical genetic study. Journal of medical genetics. $2002 \mathrm{Dec}$ $1 ; 39(12): 876-81$.
6. Jones RH. Congenital thrombocytopenia and milk allergy. Archives of disease in childhood. 1977 Sep;52(9):744. 